\title{
Diagnostic accuracy of early cognitive indicators in mild cognitive impairment
}

\author{
Marina Martorelli ${ }^{1}$, Larissa Hartle ${ }^{1,2} \odot$, Gabriel Coutinho ${ }^{3} \odot$, Daniel Correa Mograbi ${ }^{1} \odot$, \\ Daniel Chaves $^{4} \odot$, Claudia Silberman ${ }^{5}$, Helenice Charchat-Fichman ${ }^{1} \odot$
}

\begin{abstract}
The aging of the population leads to an increase in the prevalence of dementia and mild cognitive impairment (MCl). Alzheimer's disease (AD) is the most common cause of dementia. Recent studies highlight the early non-amnestic deficits in $\mathrm{AD}$ and $\mathrm{MCl}$. The European Union report shows the importance of thoroughly assessing cognitive aspects that have been poorly evaluated, such as processing speed (PS), which could represent early indicators of cognitive decline. Objective: To analyze the diagnostic accuracy of PS measures in older adults with $\mathrm{MCl}, \mathrm{AD}$, and those who are cognitively-healthy. Methods: A cross-sectional study was conducted by performing an extensive neuropsychological assessment in three samples: 26 control participants, 22 individuals with $\mathrm{MCl}$, and 21 individuals with $\mathrm{AD}$. Analysis of variance (ANOVA) was employed to test the relationship between dependent variables and the clinical group. Post hoc tests (Bonferroni test) were used when a significant ANOVA result was found. Finally, the Receiver Operating Characteristic (ROC) curve for PS measures was performed in older adults with $\mathrm{MCl}$ and $\mathrm{AD}$ compared with cognitively-healthy older adults. Results: The results showed that deficits in PS measures can be early indicators of cognitive decline in cases of $\mathrm{MCl}$, even when executive functions (EFs) and functionality are preserved. Conversely, AD versus MCI presented differences in PS, EFs, and functionality. Conclusions: The ROC analyses showed that PS measures had discriminative capacities to differentiate individuals with $M C l, A D$, and cognitively-healthy older adults.
\end{abstract}

Keywords: cognitive dysfunction, Alzheimer disease, diagnostic, cognition.

\section{ACURÁCIA DIAGNÓSTICA DE INDICADORES COGNITIVOS PRECOCES EM COMPROMETIMENTO COGNITIVO LEVE}

RESUMO. 0 envelhecimento da população leva ao aumento da prevalência de demência e comprometimento cognitivo leve (CCL). A doença de Alzheimer (DA) é a causa mais comum de demência. Estudos recentes destacam os déficits precoces não amnésicos em DA e CCL. 0 relatório da União Europeia mostra a necessidade de avaliar em maior profundidade aspectos cognitivos que atualmente são negligenciados, como a velocidade de processamento (VP), e que podem representar indicadores precoces de declínio cognitivo. Objetivo: 0 objetivo deste estudo foi analisar a acurácia diagnóstica de medidas de VP em idosos com CCL, DA e participantes controles. Métodos: um estudo transversal foi desenvolvido, no qual realizou-se uma extensa avaliação neuropsicológica em 3 amostras: 26 participantes controles, 22 casos de CCL e 21 DA. A relação entre as variáveis dependentes e 0 grupo clínico foi testada com uma análise de variância (ANOVA). Se uma ANOVA significativa fosse encontrada, testes post hoc foram utilizados. Por fim, a curva ROC para medidas de VP foi realizada em CCL e DA em comparação com indivíduos controles. Resultados: os resultados mostraram que déficits nas medidas de VP podem ser indicadores precoces do declínio cognitivo nos casos de CCL, mesmo quando as funções executivas (FE) e a funcionalidade estão preservadas. Por outro lado, DA versus CCL mostrou diferenças em VP, EF e funcionalidade. Conclusões: As análises ROC mostraram que as medidas de PS tinham capacidades discriminativas para diferenciar CCL, DA e participantes controles.

Palavras-chave: comprometimento cognitivo leve, doença de Alzheimer, diagnóstico, cognição.

\section{INTRODUCTION}

$\triangle$ ging is usually referred to as a process A of gradual deteriorations in the cognitive function that occur as people age. Profiles of cognitive aging include normal age-related cognitive declines from mild cognitive impairment (MCI) to a full stage of dementia. ${ }^{1,2}$ Alzheimer's disease (AD) is the most widespread form of dementia, ${ }^{3}$ and it is estimated that one in 85 individuals

\footnotetext{
This study was conducted at the Department of Psychology, Pontifícia Universidade Católica do Rio de Janeiro, RJ, Brazil.

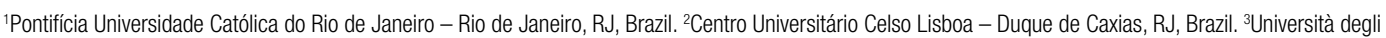
Studi di Perugia - Perugia, Italia. “Hospital Caxias D’Or - Duque de Caxias, RJ, Brazil. 5Universidade Federal do Rio de Janeiro - Rio de Janeiro, RJ, Brazil.
}

Mariana Martorelli. Avenida Marquês de São Vicente, 225 - Gávea - 22543-900 Rio de Janeiro RJ - Brazil. E-mail: marinamartorelli2@gmail.com

Disclosure: The authors report no conflicts of interest.

Funding: Coordenação de Aperfeiçoamento de Pessoal de Nível Superior (CAPES): Finance Code 001.

Received on April 21, 2020. Accepted in final form on September 08, 2020.

\section{(cc) BY}


would be living with AD by the year 2050. ${ }^{4}$ Although the average duration of the disease varies between 4 and 8 years, some patients may survive up to 20 years with the disease. ${ }^{5}$ Similarly, the aging of the population leads to the prevalence of clinical conditions such as $\mathrm{MCI}{ }^{6,7}$ $\mathrm{MCI}$ is a clinical entity according to which individuals demonstrate cognitive deficit with minimal impairment of instrumental activities of daily living (IADL) ${ }^{8,9}$ and with substantial heterogeneity in etiology, clinical presentation, prognosis, and outcome. ${ }^{10}$ The prevalence of $\mathrm{MCI}$ varies according to variables such as clinical setting and inclusion criteria. However, this prevalence generally ranges from 11 to $20 \% .{ }^{11,12}$ To better understand MCI has become a major public health priority. Its causes must be investigated, underlying pathophysiological processes and the earliest possible identification. ${ }^{13}$ Neuropsychological assessment has been effective in discriminating normal aging from mild cognitive impairment. ${ }^{14,15}$ Likewise, McKhann et al. reviewed the criteria for $\mathrm{AD}$ and found that clear-cut history of worsening of cognition by report or observation is one of the core clinical criteria for probable AD. ${ }^{16}$

Neuropsychological instruments are potentially non-invasive methods to identify individuals with $\mathrm{MCI}$ or predict the risk of developing MCI or dementia. ${ }^{17}$ Neuropsychological assessment is typically used for both descriptive and diagnostic purposes. ${ }^{18}$ When using the tests for diagnostic purposes, they provide information about the probability that an individual has - or will have at some moment in the future - to develop a cognitive disorder or deficit such as $\mathrm{AD}$ and MCI. ${ }^{19}$

The current literature recognizes neuropsychological heterogeneity in MCI by dividing it into subtypes. Most researchers employ four subtypes depending on the number of affected domains, namely: amnestic single-domain $\mathrm{MCI}(\mathrm{aMCI})$, amnestic multidomain $\mathrm{MCI}$ (aMCI), non-amnestic single-domain $\mathrm{MCI}$ (naMCI), and non-amnestic multidomain MCI (naMCI). ${ }^{9,20-24}$ The European Union (EU) report highlights the need to assess non-amnestic aspects in MCI, such as motor/perceptual aspects or processing speed (PS), considering that such features may not be thoroughly investigated and could represent early indicators of cognitive decline. ${ }^{25}$ Most neuropsychological studies involving MCI have focused on disorders of episodic memory, language, and executive functions. ${ }^{26-31}$ Actually, information processing speed is included in the diagnostic criteria for neurocognitive disorders of the Diagnostic and Statistical Manual of Mental Disorders (DSM-5). ${ }^{16}$ However, there is substantially less research that evaluates deficits in PS in MCI. ${ }^{32-34}$ Likewise, recent studies highlight the cognitive heterogeneity in $\mathrm{AD}$, showing the importance of studying other cognitive aspects in addition to episodic memory. ${ }^{35-38}$

Normal aging and some psychiatric disorders (such as MCI and AD) were associated with decline in PS..$^{39,40}$ PS involves several components of executive control, which vary according to age. Individual differences in PS indicate variation in neural speed, ${ }^{41,42}$ as well as age-related changes in neural processing, including the decline of axonal myelination throughout life. ${ }^{40,41}$ PS can be conceptualized as either the amount of time it takes to process a specific quantity of information ${ }^{39,40}$ or the quantity of information that can be processed within a finite amount of time. ${ }^{43}$ Decline in PS leads to cognitive deficits that make the ability to simultaneously control information limited. Taking into consideration the lower capacity to process information, it can also conduct to increased errors in the cognitive processing. ${ }^{39,40}$

Accurate diagnosis of $\mathrm{MCI}$ and $\mathrm{AD}$ is very important for timely therapy and possible delay of the disease. ${ }^{44}$ Consequently, the analysis of PS measures in aging is crucially important, especially in the Brazilian context, and neuropsychological tests are fundamental in this process. Based on a brief review of the literature, there are no Brazilian study on the subject to the best of our knowledge. Therefore, the purpose of this study is to analyze the diagnostic accuracy of early neuropsychological indicators, such PS measures, in older adults affected by $\mathrm{AD}, \mathrm{MCI}$, and in those who are cognitively-healthy.

\section{METHODS}

\section{Participants}

A total of 85 individuals were selected from a social program that was offered by the Government of Rio de Janeiro, Brazil. Of these individuals, 36 were control participants $(\mathrm{CP}), 26$ had MCI, and 21 had a probable diagnosis of $\mathrm{AD}$. The assessments were performed between 2016 and 2018 in Rio de Janeiro (state of Rio de Janeiro, Brazil) by a certified board psychiatrist and all neuropsychological evaluations were conducted by a senior neuropsychologist in Rio de Janeiro. The match of the variables "age" and "years of education" was performed; thus, 12 control participants and four individuals with $\mathrm{MCI}$ were excluded from the sample (Figure 1). Although the AD group presented a higher mean age, individuals with such diagnosis were not excluded, in such a way $21 \mathrm{AD}$ cases of baseline were maintained. Therefore, the sample resulted in $26 \mathrm{CP}$ and 22 individuals with MCI. All participants aged over 60 years and were proficient in Brazilian Portuguese. The participants agreed to participate in the study 


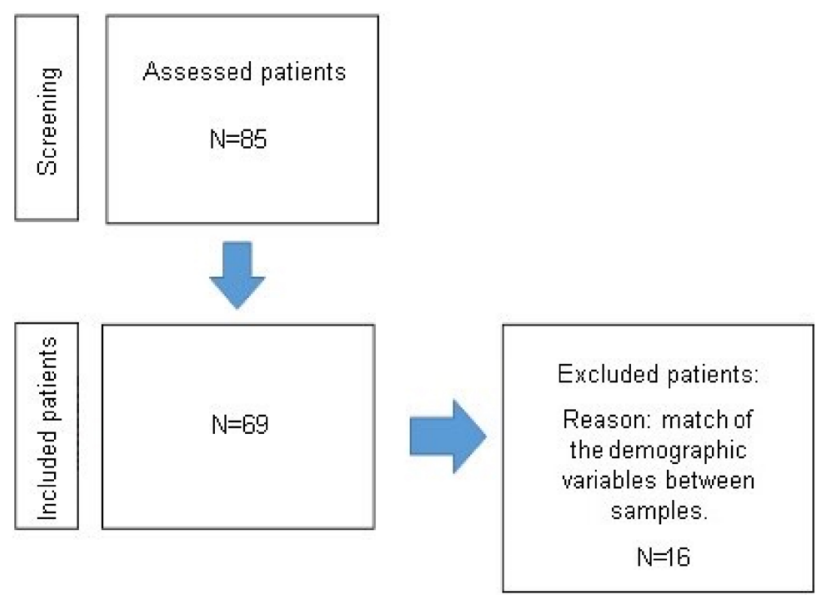

Figure 1. Flowchart of criteria for sample selection.

and signed the informed consent form. The study was approved by the Research Ethics Committee under authorization No. 965.264.

\section{Diagnosis}

Control participants $(\mathrm{CP})$ were individuals with no changes in cognitive performance tests and without functional impairment. The assessment of $\mathrm{CP}$ and individuals with MCI was based on clinical history, neuroimaging, and an initial neuropsychological protocol that included the following tests and scales: 1) Mini-Mental State Examination (MMSE); ${ }^{45}$ 2) Brief Cognitive Screening Battery, which consisted of the following tests: Memory of Figure Test (MFT); Categorical Verbal Fluency Test (CVFT); Clock Drawing Test (CDT); Geriatric Depression Scale (GDS-15); Pfeffer's Functional Activities Questionnaire (FAQ); and Lawton Instrumental Activities of Daily Living Scale (IADL); ${ }^{46,47}$ 3) Rey Auditory Verbal Learning Test (RAVLT); ${ }^{48} 4$ ) Phonemic Verbal Fluency Test (FAS); ${ }^{49}$ and 5) Rey Complex Figure Task. ${ }^{50}$ All participants with $\mathrm{MCI}$ who had subjective cognitive complaints underwent a comprehensive neuropsychological assessment. A clinical diagnosis of individuals with $\mathrm{MCI}$ was established at a conference for each patient by an interdisciplinary team. Finally, the diagnosis of $\mathrm{AD}$ was based on the consensus criteria from the National Institute of Neurological and Communicative Disorders and Stroke and the Alzheimer's Disease and Related Disorders Association (NINCDS-ADRDA). ${ }^{16}$ Exclusion criteria included: 1) history of cerebral infection or stroke; 2) brain tumor; 3) head injury; 4) ongoing psychiatric illness; 5) history of alcohol or drug abuse; and 6) brain imaging that indicated any possibility of brain lesions other than MCI.

\section{Neuropsychological tests used in measures of processing speed and executive functions}

PS was assessed by the tests of the Wechsler Adult Intelligence Scale, Third Edition (WAIS-III) ${ }^{51}$ namely: Digit Symbol-Coding (CD) and Symbol Search (SS). In addition, the Processing Speed Index (PSI) was performed for all participants in the sample. Finally, the attention and executive functions were assessed by the Color Trails Test (CTT), ${ }^{52}$ the Victoria Stroop Test (VST, Dot condition - Card 1; Word condition - Card 2; Interference condition - Card 3), ${ }^{53}$ and the Digit Span Test (DS). ${ }^{51}$

\section{Analyses}

All analyses were conducted with the Statistical Package for the Social Sciences (SPSS) software, v. 21,, with significance set at $\mathrm{p} \leq 0.05$. Normality of distribution was determined by a histogram. According to the data, there was no normal distribution, in such a way that parametric and nonparametric tests were performed. The results of the analyses only differed in CTT - Form A (individuals with MCI) and VST (Card 1; individuals with MCI). Measures of Skewness and Kurtosis were analyzed and indicated the use of parametric tests. Data analysis was performed using raw scores of the neuropsychological tests, and only PSI was converted into standard scores. The relationship between dependent variables and the clinical group was tested with analysis of variance (ANOVA). If a significant ANOVA was found, post hoc tests (Bonferroni test) controlling for multiple comparisons were used to identify pairs of clinical groups that significantly differed. Clinical groups were also compared according to demographic characteristics (i.e., age, sex, and years of education). Finally, the Receiver Operating Characteristic (ROC) curve was performed for the following tests and index: $C D, S S$, and PSI. ROC curves were also plotted in order to determine the degree to which subtests discriminated between $\mathrm{CP}$, individuals with $\mathrm{MCI}$, and individuals with $\mathrm{AD}$. These analyses show the sensitivity versus one minus the specificity for each possible cutoff point. The area under the curve (AUC), with 95\% confidence intervals (95\%CI), was used as an indicator of the ability of the $\mathrm{PS}$ measures in differentiating patients who were $\mathrm{CP}$, individuals with $\mathrm{MCI}$, and individuals with $\mathrm{AD}$.

\section{RESULTS}

\section{Demographic characteristics, Mini-Mental State Examination, and Lawton scores}

Table 1 summarizes demographic data, Lawton score (patient version), MMSE score, and pairwise 
Table 1. Demographic characteristics (mean and standard deviation), Mini-Mental State Examination scores (maximum: 35 points), Lawton scores (patient version; maximum: 21 points), and pairwise comparisons for the three study groups.

\begin{tabular}{lccccccc}
\hline & $\mathbf{C P}(\mathbf{n = 2 6 )}$ & $\mathbf{M C l}(\mathbf{n = 2 2 )}$ & $\mathbf{A D}(\mathbf{n = 2 1 )}$ & $\mathbf{F}$ & ${ }^{*} \mathbf{p}$-value & $\begin{array}{c}\text { * } \mathbf{p} \text {-value } \\
\text { (CP versus MCI) }\end{array}$ & $\begin{array}{c}{ }^{*} \mathbf{p} \text {-value } \\
\text { (MCI versus AD) }\end{array}$ \\
\hline Age & $73.3(4.9)$ & $75.6(6.2)$ & $79.2(6.7)$ & 5.7 & $\mathbf{0 . 0 0 4}$ & 0.568 & 0.147 \\
\hline Years of education & $13.1(3.0)$ & $10.4(5.1)$ & $11.4(4.5)$ & 2.5 & 2.5 & 0.087 & 1.00 \\
\hline MMSE score (max: 35 points) & $31.6(1.8)$ & $29.6(2.6)$ & $24.4(5.9)$ & 21.5 & $<\mathbf{0 . 0 0 1}$ & 0.225 & $<0.001$ \\
\hline Lawton score (max: 21 points) & $20.8(0.4)$ & $20.3(0.6)$ & $18.0(2.2)$ & 28.1 & $<\mathbf{0 . 0 0 1}$ & 0.665 & $<0.001$ \\
\hline Men & $4(22)$ & $1(21)$ & $7(14)$ & $*$ & $*$ & $*$ & $*$
\end{tabular}

*MMSE: Mini-Mental State Examination; CP: Control Participants; MCl: mild cognitive impairment; AD: Alzheimer's disease.

comparisons. The repeated measures ANOVA showed differences between age $(F(2.66)=5.7 ; \mathrm{p}=.005)$; MMSE score $(F(2.66)=21.5 ; \mathrm{p}<.001)$, and Lawton score $(F(2.65)=28.1 ; \mathrm{p}<.001)$, but not in years of education $(F(2.66)=2.5 ; \mathrm{p}=.084)$. When comparing individuals with $\mathrm{MCI}$ versus $\mathrm{CP}$, pairwise comparisons presented no differences in age $(\mathrm{p}=.56)$, years of education $(\mathrm{p}=.09)$, MMSE score $(\mathrm{p}=.22)$, and Lawton score $(\mathrm{p}=.66)$. As expected, AD versus MCI showed differences in MMSE scores $(\mathrm{p}<.001)$ and Lawton scores $(\mathrm{p}<.001)$, but not in age $(\mathrm{p}=.14)$ and years of education $(\mathrm{p}=1.00)$.

\section{Executive functions and processing speed measures}

Table 2 shows mean and standard deviation (SD) of neuropsychological measures and pairwise comparisons. The ANOVA demonstrated differences in PSI $(F(2.66)=25.1 ; \mathrm{p}<.001)$, SS score $(F(2.66)=17.2$; $\mathrm{p}<.001), C D$ score $(F(2.66)=26.3 ; \mathrm{p}<.001)$, SS errors $(F(2.66)=3.6 ; \mathrm{p}=.030)$, VST-Card $1(F(2.57)=6.3$; $\mathrm{p}=.003)$, VST-Card $2(F(2.57)=6.6 ; \mathrm{p}=.002)$, VST-Card $3(F(2.57)=9.5 ; \mathrm{p}<.001), C T T-$ Form A $(F(2.66)=15.5$; $\mathrm{p}<.001), C T \mathrm{~T}-$ Form B $(F(2.66)=18.0 ; \mathrm{p}<.001)$, CTT - Form A errors $(F(2.66)=4.1 ; \mathrm{p}=.021)$, and DS $(F(2.66)=5,5 ; \mathrm{p}=.006)$, but no differences in CTT Form B errors $(F(2.66)=3.0 ; \mathrm{p}=.055)$. When comparing individuals with $\mathrm{MCI}$ and $\mathrm{CP}$, only PS measures showed differences, such as: SS score $(\mathrm{p}=.001), C D$ score $(\mathrm{p}<.001)$, PSI $(\mathrm{p}<.001)$, and SS errors $(\mathrm{p}=.028)$. There were no differences in EFs measures, except for DS ( $\mathrm{p}=.04)$. This ability to identify early MCI in individuals can be explained by differences in the performance of PS measures, which is sufficient to distinguish the groups. However, the comparison between $\mathrm{MCI}$ and $\mathrm{AD}$ demonstrated differences in PS and EFs measures, such as: CD score $(\mathrm{p}=.010)$, PSI $(\mathrm{p}=.036), \mathrm{CTT}$ - Form
A ( $\mathrm{p}=.002)$, CTT - Form B ( $<<.001)$, VST-Card 2 $(\mathrm{p}=.012)$, and VST-Card $3(\mathrm{p}=.002)$.

\section{Mild cognitive impairment versus control participants}

Sensitivity and specificity of the processing speed measures were investigated in the first analysis, namely: SS, CD, and PSI. These diagnostic parameters were used to test the ability of these PS measures in identifying individuals with MCI compared with cognitively-healthy older adults (Figure 2). The estimated AUC for SS was 0.80 (95\%CI 0.68-0.93; p<0.01) and for $C D, 0.79$ (95\%CI 0.66-0.92; $\mathrm{p}<0.01$ ). In addition, the estimated AUC for PSI was 0.83 (95\%CI $0.71-0.94 ; \mathrm{p}<0.01)$. The most appropriate cutoff point (raw score) for SS was 19.5, with sensitivity and specificity of 86 and $76 \%$ respectively; as for $\mathrm{CD}$ (raw score), the most appropriate cutoff point was 36.5 , with sensitivity and specificity of 77 and $80 \%$ respectively. Finally, the most appropriate cutoff point for PSI was 114.5 , with sensitivity and specificity of 81 and $76 \%$ respectively.

\section{Alzheimer's disease versus control participants}

The diagnostic parameters were used to test the ability of PS measures in identifying cases of Alzheimer's disease compared with cognitively-healthy older adults. The estimated AUC compared with cognitively-healthy older adults. The estimated AUC (Figure 3) for SS was 0.88 (95\%CI 0.78-0.98; p<0.01); for CD, 0.92 (95\%CI 0.85-0.99; $<<0.01)$. Finally, the estimated AUC for PSI was 0.90 (95\%CI 0.81-0.99; $\mathrm{p}<0.01$ ). The most appropriate cutoff point for SS (raw score) was 17.0, with sensitivity and specificity of 85 and $80 \%$ respectively; as for $\mathrm{CD}$ (raw score), the most appropriate cutoff point was 35.5 , with sensitivity and specificity of 85 and $80 \%$ respectively. Finally, the most appropriate cutoff point 
Table 2. Mean and standard deviation of neuropsychological measures and pairwise comparisons.

\begin{tabular}{|c|c|c|c|c|c|}
\hline Neuropsychological measures & $C P(n=26)$ & $\operatorname{MCl}(n=22)$ & $A D(n=21)$ & $\begin{array}{c}{ }^{*} \mathrm{p} \text {-value } \\
\text { (CP versus MCl) }\end{array}$ & $\begin{array}{c}{ }^{*} p \text {-value } \\
\text { (MCl versus AD) }\end{array}$ \\
\hline PSI (max: 146 points) & $123.0(12.5)$ & $107.1(11.2)$ & $97.1(14.2)$ & $<0.001$ & 0.036 \\
\hline CD (max: 133 points) & $45.7(13.7)$ & $30.7(11.5)$ & $18.8(12.7)$ & $<0.001$ & 0.010 \\
\hline SS (max: 60 points) & $24.8(9.9)$ & $15.5(6.1)$ & $11.2(7.5)$ & 0.001 & 0.277 \\
\hline SS errors & $1.5(1.5)$ & $3.0(1.7)$ & $2.4(2.2)$ & 0.028 & 0.931 \\
\hline CTT - Form A & $67.0(27.0)$ & $94.9(27.6)$ & $153.9(88.3)$ & 0.231 & 0.002 \\
\hline CTT - Form B & $130.9(45.2)$ & $170.3(38.3)$ & $266.2(126.2)$ & 0.257 & $<0.001$ \\
\hline CTT - Form A errors & $0.04(0.1)$ & $0.14(0.4)$ & $0.6(1.2)$ & 1.00 & 0.097 \\
\hline CTT - Form B errors & $0.15(0.3)$ & $0.64(1.0)$ & $1.9(4.3)$ & 1.00 & 0.291 \\
\hline VST-Card 1 & $14.8(3.6)$ & $21.7(8.4)$ & $32.3(25.0)$ & 0.506 & 0.095 \\
\hline VST-Card 2 & $21.0(6.3)$ & $24.7(7.3)$ & $53.2(51.6)$ & 1.00 & 0.012 \\
\hline VST-Card 3 & $33.6(13.4)$ & $40.2(12.8)$ & $87.3(70.8)$ & 1.00 & 0.002 \\
\hline Interference & $2.0(0.9)$ & $2.5(2.3)$ & $2.7(1.1)$ & 1.00 & 0.05 \\
\hline DS (max: 14 points) & $12.4(3.7)$ & $10.1(2.6)$ & $9.6(2.7)$ & 0.04 & 1.00 \\
\hline
\end{tabular}

*VST: Victoria Stroop Test; CTT: Color Trails Test; SS: Search Symbols (maximum: 60 points); CD: Digit Symbol-Coding (maximum: 133 points); PSI: Processing Speed Index (maimum: 146); DS: Digit Span Test (maximum: 14 points).

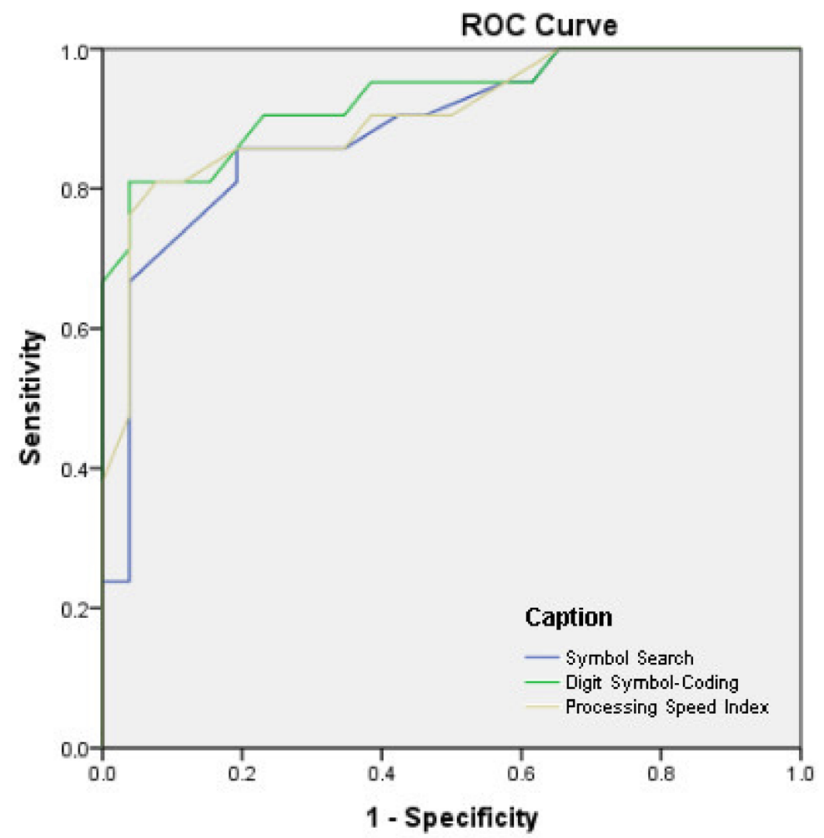

Figure 2. Analyses of Receiver Operating Characteristic curve, sensitivity, and specificity for Alzheimer's disease versus control participants.

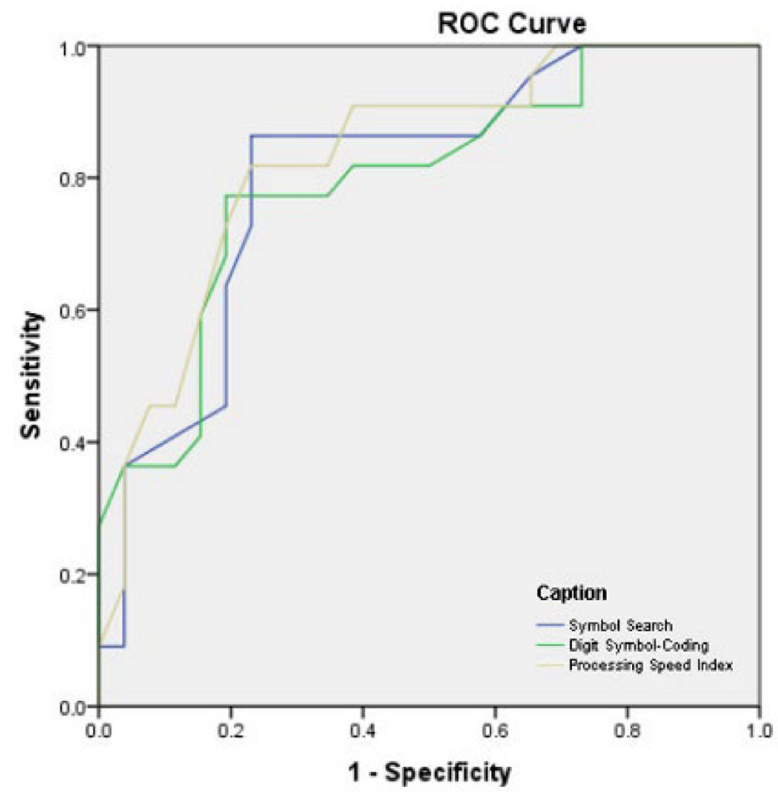

Figure 3. Analyses of Receiver Operating Characteristic curve, sensitivity, and specificity for individuals with mild cognitive impairment versus control participants. 
for PSI was 112, with sensitivity and specificity of 85 and $80 \%$ respectively.

\section{DISCUSSION}

The results of this study might indicate that individuals with $\mathrm{MCI}$ could be early identified according to the performance in PSI and in tests that assess PS, when compared with the control participants. According to Salthouse, ${ }^{39,40}$ the decrease in PS can also lead to increased errors in the cognitive processing. Moreover, according to data of the present study, samples of individuals with $\mathrm{MCI}$ and $\mathrm{CP}$ can be differentiated by the number of errors made in one of the PS tests. However, differences in traditional measures of executive functions were not enough to distinguish control participants from individuals with MCI, except for DS. This fact can be explained because complex measures of EFs, such as working memory, require process of attention and mental manipulation. ${ }^{54}$ Furthermore, the ROC analyses showed that PS measures had discriminative capacities to differentiate individuals with $\mathrm{MCI}, \mathrm{AD}$, and cognitively-healthy older adults.

Cognitive domains decrease with advanced age. ${ }^{55,56}$ Decline in cognitive function affects more than $50 \%$ of people aged over 60 years. ${ }^{57}$ Particularly, memory and PS seem to be more sensitive to age than other cognitive domains. ${ }^{39,55} \mathrm{~A}$ recent study have compared cognitively-healthy older adults, individuals with $\mathrm{MCI}$, and individuals with $\mathrm{AD}$, and showed that PS measures were significant to differentiate the three groups. White matter (WM) brain pathology is often present in patients with $\mathrm{MCI}$ and $\mathrm{AD}$. Thus, this study concluded that WM seemed to have the strongest effects on PS measures for the three samples. ${ }^{33}$ Likewise, Park et al. assessed cognitively-healthy older adults, individuals with $\mathrm{MCI}$, and those with $\mathrm{AD}$, and concluded that a PS measure could distinguish the three groups. ${ }^{34}$ These results support our findings and the notion that neuropsychological measures are sensitive to differentiate individuals with $\mathrm{AD}, \mathrm{MCI}$, and cognitively-healthy older adults.
According to the American Psychiatric Association (APA) and the NINCDS-ADRDA, neuropsychological assessment is necessary and consists in an important component for the diagnosis of $\mathrm{MCI}$ and $\mathrm{AD}$, respectively ${ }^{16,58}$ Furthermore, neuropsychological testing is an equally valuable and arguably more affordable and less invasive cognitive biomarker of $\mathrm{AD} .{ }^{20}$ In this context, the strength of the study was to provide diagnostic parameters for early neuropsychological indicators in the Brazilian samples. In addition, it provides raw data on the performance of individuals with MCI compared with cognitively-healthy older adults.

However, limitations of this study should be discussed. First, the Brazilian norms of the WAIS-III have limitations and must be revised. In order to minimize these biases, only the raw data from the CD and SS tests were analyzed. Second, the study sample size. Clinical samples and extensive neuropsychological evaluations present major obstacles to evidence-based neuropsychology practice. Noteworthily, the sample of the present study is mainly composed of women. Nevertheless, previous studies showed that women have better performance than men on verbal memory tasks, but sex differences were not evident for speed of information processing and attention. ${ }^{59,60}$

In conclusion, the authors emphasize the importance of early indicators of cognitive decline in MCI and the diagnostic parameters in the neuropsychological instruments in the Brazilian clinical settings. Such aspects might impact the prognosis of the disorder and assist in decision-making concerning treatment options, especially those related to cognitive rehabilitation. Nevertheless, further studies on the subject are still necessary.

Authors' contributions. MM: data curation, formal analysis, writing - original draft, and writing — review \& editing. LH: formal analysis, methodology and investigation. GC: formal analysis, methodology and investigation. DM: formal analysis, methodology and investigation. DC: formal analysis, methodology and investigation. CS: formal analysis, methodology and investigation. HC: project administration and supervision.

\section{REFERENCES}

1. Chatterji S, Kowal P, Mathers C, Naidoo N, Verdes E, Smith JP, et al. The health of aging populations in China and India. Health Aff (Millwood). 2008; 27(4):1052-63. https://doi.org/10.1377/hlthaff.27.4.1052

2. Zhang D, Shen D. Multi-modal multi-task learning for joint prediction of multiple regression and classification variables in Alzheimer's disease. Neuroimage. 2012;59(2):895-907. https://doi.org/10.1016/j.neuroimage.2011.09.069
3. Townsend M. When will Alzheimer's disease be cured? A pharmaceutical perspective. J Alzheimers Dis. 2011;24 Suppl. 2:43-52. https://doi. org/10.3233/JAD-2011-110020

4. Brookmeyer R, Johnson E, Ziegler-Graham K, Arrighi HM. Forecasting the global burden of Alzheimer's disease. Alzheimer's Dement. 2007;3(3):186-91. https://doi.org/10.1016/j.jalz.2007.04.381 
5. Xie J, Brayne C, Matthews FE. Survival times in people with dementia: analysis from population based cohort study with 14 year follow-up. BMJ. 2008;336(7638):258-62. https://doi.org/10.1136/bmj.39433.616678.25

6. Sachdev PS, Lipnicki DM, Kochan NA, Crawford JD, Thalamuthu A, Andrews $\mathrm{G}$, et al. The prevalence of mild cognitive impairment in diverse geographical and ethnocultural regions: The COSMIC Collaboration. PLoS One. 2015;10(11):e0142388. https://doi.org/10.1371/journal. pone.0142388

7. Petersen RC, Lopez O, Armstrong MJ, Getchius TSD, Ganguli M, Gloss $D$, et al. Practice guideline update summary: mild cognitive impairment: report of the Guideline Development, Dissemination, and Implementation Subcommittee of the American Academy of Neurology. Neurology. 2018;90(3):126-35. https://doi.org/10.1212/WNL.0000000000004826

8. Petersen RC. Mild cognitive impairment as a diagnostic entity. J Intern Med. 2004;256(3):183-94. https://doi.org/10.1111/j.1365-2796.2004.01388.x

9. Winblad B, Palmer K, Kivipelto $M$, Jelic V, Fratiglioni L, Wahlund L-O, et al. Mild cognitive impairment: beyond controversies, towards a consensus: report of the International Working Group on Mild Cognitive Impairment. J Intern Med. 2004;256(3):240-6. https://doi.org/10.1111/j. 1365-2796.2004.01380.x

10. Petersen RC. Mild cognitive impairment: where are we? Alzheimer Dis Assoc Disord. 2005;19(3):166-9. https://doi.org/10.1097/01. wad.0000179417.95584.90

11. Petersen RC, Roberts RO, Knopman DS, Geda YE, Cha RH, Pankratz VS, et al. Prevalence of mild cognitive impairment is higher in men. Neurology. 2010;75(10):889-97. https://doi.org/10.1212/WNL.0b013e3181f11d85

12. Nie H, Xu Y, Liu B, Zhang Y, Lei T, Hui X, et al. The prevalence of mild cognitive impairment about elderly population in China: a meta-analysis. Int J Geriatr Psychiatry. 2011;26(6):558-63. https://doi.org/10.1002/ gps.2579

13. Winblad B, Amouyel P, Andrieu S, Ballard C, Brayne C, Brodaty H, et al. Defeating Alzheimer's disease and other dementias: a priority for European science and society. Lancet Neurol. 2016;15(5):455-532. https://doi. org/10.1016/S1474-4422(16)00062-4

14. De Jager CA, Hogervorst E, Combrinck M, Budge MM. Sensitivity and specificity of neuropsychological tests for mild cognitive impairment, vascular cognitive impairment and Alzheimer's disease. Psychol Med. 2003;33(6):1039-50. https://doi.org/10.1017/s0033291703008031

15. Salmon DP, Bondi MW. Neuropsychological assessment of dementia. Annu Rev Psychol. 2009;60:257-82. https://doi.org/10.1146/annurev. psych.57.102904.190024

16. McKhann GM, Knopman DS, Chertkow H, Hyman BT, Jack CR, Kawas $\mathrm{CH}$, et al. The diagnosis of dementia due to Alzheimer's disease: Recommendations from the National Institute on Aging-Alzheimer's Association workgroups on diagnostic guidelines for Alzheimer's disease. Alzheimers Dement. 2011;7(3):263-9. https://doi.org/10.1016/j.jalz.2011.03.005

17. Blacker D, Lee H, Muzikansky A, Martin EC, Tanzi R, McArdle JJ, et al. Neuropsychological measures in normal individuals that predict subsequent cognitive decline. Arch Neurol. 2007;64(6):862-71. https://doi. org/10.1001/archneur.64.6.862

18. Busch RM, Chelune GJ, Suchy Y. Using norms in neuropsychological assessment of the elderly. In: Attix DK, Welsh-Bohmer KA (Eds.). Geriatric neuropsychology: assessment and intervention. New York: Guilford Publications; 2006. p. 133-57.

19. Stern RA, White T. Neuropsychological assessment battery. Lutz, FL: Psychological Assessment Resources; 2003.

20. Jak AJ, Preis SR, Beiser AS, Seshadri S, Wolf PA, Bondi MW, et al. Neuropsychological Criteria for Mild Cognitive Impairment and Dementia Risk in the Framingham Heart Study. J Int Neuropsychol Soc. 2016;22(9):937-43. https://doi.org/10.1017/S1355617716000199

21. Lopez OL, Becker JT, Chang YF, Sweet RA, DeKosky ST, Gach, MH, et al. Incidence of mild cognitive impairment in the Pittsburgh Cardiovascular Health Study-Cognition Study. Neurology. 2012;79(15):1599-606. https:// doi.org/10.1212/WNL.0b013e31826e25f0

22. Bangen KJ, Jak AJ, Schiehser DM, Delano-Wood L, Tuminello E, Han $\mathrm{SD}$, et al. Complex activities of daily living vary by mild cognitive impairment subtype. J Int Neuropsychol Soc. 2010;16(4):630-9. https://doi. org/10.1017/S1355617710000330

23. Petersen RC, Negash S. Mild cognitive impairment: an overview. CNS Spectr. 2008;13(1):45-53. https://doi.org/10.1017/s1092852900016151

24. Busse A, Hensel A, Guhne U, Angermeyer MC, Riedel-Heller SG. Mild cognitive impairment: long-term course of four clinical subtypes. Neurology. 2006;67(12):2176-85. https://doi.org/10.1212/01. wnl.0000249117.23318.e

25. Apostolo J, Holland C, O'Connell MD, Feeney J, Tabares-Seisdedos R, Tadros G, et al. Mild cognitive decline. A position statement of the Cognitive Decline Group of the European Innovation Partnership for Active and Healthy Ageing (EIPAHA). Maturitas. 2016;83:83-93. https://doi. org/10.1016/j.maturitas.2015.10.008

26. Eppig J, Wambach, D, Nieves C, Price CC, Lamar M, Delano-Wood L, et al. Dysexecutive functioning in mild cognitive impairment: Derailment in temporal gradients. J Int Neuropsychol Soc. 2012;18(1):20-8. https:// doi.org/10.1017/S1355617711001238

27. Hwang YK, Kim E, Kim YB, Kim YW, Nam CM, Cho SH, et al. Diag nostic value of time-constrained naming test in mild cognitive impairment. Dement Geriatr Cogn Disord. 2017;44:171-81. https://doi. org/10.1159/000479149

28. Kirova AM, Bays RB, Lagalwar S. Working memory and executive function decline across normal aging, mild cognitive impairment, and Alzheimer's disease. BioMed Res Int. 2015:748212. https://doi. org/10.1155/2015/748212

29. Libon DJ, Bondi MW, Price, CC, Lamar M, Eppig J, Wambach DM, et al. Verbal serial list learning in mild cognitive impairment: A profile analysis of interference, forgetting, and errors. J Int Neuropsychol Soc. 2011;17(5):905-14. https://doi.org/10.1017/S1355617711000944

30. McCullough KC, Bayles KA, Bouldin ED. Language performance of individuals at risk for mild cognitive impairment. J Speech Lang Hear R. 2019;62(3):706-22. https://doi.org/10.1044/2018_JSLHR-L-18-0232

31. Saunders NLJ, Summers MJ. Longitudinal deficits to attention, executive, and working memory in subtypes of mild cognitive impairment. Neuropsychology. 2011;25(2):237-48. https://doi.org/10.1037/a0021134

32. Dion C, Arias F, Amini S, Davis R, Penney D, Libon DJ, et al. Cognitive correlates of digital clock drawing metrics in older adults with and without mild cognitive impairment. J Alzheimers Dis. 2020;75(1):73-83. https:// doi.org/10.3233/JAD-191089

33. Kaskikallio A, Karrasch M, Rinne J, Tuokkola T, Parkkola R, Grönholm-Nyman P. Domain-specific cognitive effects of white matter pathology in old age, mild cognitive impairment and Alzheimer's disease. Neuropsycho Dev Cogn B Aging Neuropsychol Cogn. 2020;27(3):453-70. https://doi. org/10.1080/13825585.2019.1628916

34. Park S, Pyo S, Shin SA, Lee JY, Kim YK, Park, HJ, et al. A quick test of cognitive speed in older adults with Alzheimer's disease and mild cognitive impairment: a preliminary behavioral and brain imaging study. Psychiatry Res Neuroimag. 2018;280:30-8. https://doi.org/10.1016/j.pscychresns.2018.08.004

35. Martorelli M, Sudo FK, Fichman-Charchat $\mathrm{H}$. This is not only about memory: a systematic review on neuropsychological heterogeneity in Alzheimer's disease. Psychol Neurosci. 2019;12(2):271-81. https://doi. org/10.1037/pne0000149

36. Scheltens NME, Tijms BM, Koene T, Barkhof F, Teunissen CE, Wolfsgruber $\mathrm{S}$, et al. Cognitive subtypes of probable Alzheimer's disease robustly identified in four cohorts. Alzheimers Dement. 2017;13(11):1226-36. https:// doi.org/10.1016/j.jalz.2017.03.002

37. Scheltens NM, Galindo-Garre F, Pijnenburg YA, van der Vlies AE, Smits $\mathrm{LL}$, Koene T, et al. The identification of cognitive subtypes in Alzheimer's disease de-mentia using latent class analysis. J Neurol Neurosurg Psychiatry. 2016;87(3):235-43. https://doi.org/10.1136/jnnp-2014-309582

38. Vardy E, Ford AH, Gallagher P, Watson R, McKeith IG, Blamire A, et al. Distinct cognitive phenotypes in Alzheimer's disease in older people. Int Psychogeriatr. 2013;25(10):1659-66. https://doi.org/10.1017/ S1041610213000914

39. Salthouse TA. The processing-speed theory of adult age differences in cognition. Psychol Rev. 1996;103(3):403-28. https://doi.org/10.1037/ 0033-295x.103.3.403

40. Salthouse TA. What and when of cognitive aging. Curr Dir Psychol Sci. 2004:13(4):140-44. https://doi.org/10.1111/j.0963-7214.2004.00293.x

41. Birren JE, Fisher LM. Aging and speed of behavior: Possible consequences for psychological functioning. Ann Rev Psychol. 1995;46:329-53. https:// doi.org/10.1146/annurev.ps.46.020195.001553

42. Mendelson JR, Ricketts C. Age-related temporal processing speed deterioration in auditory cortex. Hear Res. 2001;158(1-2):84-94. https:// doi.org/10.1016/S0378-5955(01)00294-5

43. Kalmar JH, Chiaravalloti ND. Information processing speed in multiple sclerosis: a primary deficit? In: DeLuca J, Kalmar JH (Eds.). Studies on neuropsychology, neurology and cognition. Information processing speed in clinical populations. [N.I.] Taylor \& Francis; 2008. p. 153-72.

44. Zhang D, Shen D, Alzheimer's Disease Neuroimaging Initiative. Predicting future clinical changes of $\mathrm{MCl}$ patients using longitudinal and multimodal biomarkers and brain imaging study. PLoS One. 2012;7(3):e33182. https://doi.org/10.1371/journal.pone.0033182

45. Brucki S, Ricardo N, Caramelli P, Bertolucci P, Okamoto $\Vdash H$. Suggestions for the use of the mental state mini-exam in Brazil. Arq Neuro-Psiquiatr 2003;61(3-B):777-81. https://doi.org/10.1590/S0004$282 \times 2003000500014$ 
46. Nitrini $R$, Lefèvre $B$, Mathias $S$, Caramelli $P$, Carrilho $P$ Sauaia, et al. Neuropsychological tests of simple application for diagnosing dementia Arq Neuro-Psiquiatr. 1994;52(4):457-65. https://doi.org/10.1590/s0004282x1994000400001

47. Araujo VC, Lima CMB, Barbosa ENB, Furtado FP, Charchat-Fichman H Impact of age and schooling on performance on the Brief Cognitive Screening Battery: A study of elderly residents in the City of Rio de Janeiro, Brazil. Psychol Neurosci. 2018;11(3):317-28. https://doi.org/10.1037/pne0000118

48. De Paula J, Malloy-Diniz. Rey Auditory Verbal Learning Test. São Paulo; 2018. Vetor.

49. Machado TH, Fichman HC, Santos EL, Carvalho VA, Fialho PP, Koenig AM, et al. Normative data for healthy elderly on the phonemic verbal fluency task FAS. Dement Neuropsychol. 2009;3(1):55-60. https://doi. org/10.1590/S1980-57642009DN30100011

50. Oliveira M, Rigoni M. Rey's figure copy and memory reproduction. São Paulo: Casa do Psicólogo; 2017.

51. Wechsler D. WAIS-III: Wechsler Adult Intelligence Scale - Third edition administration and scoring manual. São Paulo: Psychological Corporation; 2004

52. Rabelo I, Pacanaro S, Rosseti M, De Sá, I. Trail color test. São Paulo: Casa do Psicólogo; 2010.

53. Regard M. Cognitive rigidity and flexibility: a neuropsychological study Unpublished Ph.D. dissertation - University of Victoria, British Columbia; 1981.

54. Carlozzi NE, Tulsky DS, Chiaravalloti ND, Beaumont JL, Weintraub S, Conway K, et al. NIH Toolbox Cognitive Battery (NIHTB-CB): the NIHTB pattern comparison processing speed test. J Int Neuropsychol Soc. 2014;20(6):630-41. https://doi.org/10.1017/S1355617714000319

55. Christensen $\mathrm{H}$. What cognitive changes can be expected with normal ageing? Aust N Z J Psychiatry. 2001;35(6):768-75. https://doi.org/10.1046/j.1440-1614.2001.00966.x

56. Singh-Manoux A, Kivimaki M, Glymour M, Elbaz A, Berr C, Ebmeier K, et al. Timing of onset of cognitive decline: results from Whitehall II prospective cohort study. BMJ. 2012;344:d7622. https://doi.org/10.1136/ bmj.d7622

57. Skaper SD, Facci L, Giusti P. Neuroinflammation, microglia and mast cells in the pathophysiology of neurocognitive disorders: a review. CNS Neurol Disord Drug Targets. 2014;13(10):1654-66. https://doi.org/10.2174/187 1527313666141130224206

58. American Psychiatric Association. Diagnostic and statistical manual of mental disorders. 5. ed. Washington, DC: APA; 2013.

59. van Hooren SA, Valentijn AM, Bosma H, Ponds RW, van Boxtel MP, Jolles J. Cognitive functioning in healthy older adults aged 64-81: a cohort study into the effects of age, sex, and education. Neuropsychol Dev Cogn B Aging Neuropsychol Cogn. 2007;14(1):40-54. https://doi. org/10.1080/138255890969483

60. Mougias A, Christidi F, Synetou M, Kotrotsou I, Valkimadi P, Politis A. Differential effect of demographics, processing speed, and depression on cognitive function in 755 non-demented community-dwelling elderly individuals. Cogn Behav Neurol. 2019;32(4):236-46. https://doi.org/10.1097/ WNN.0000000000000211 